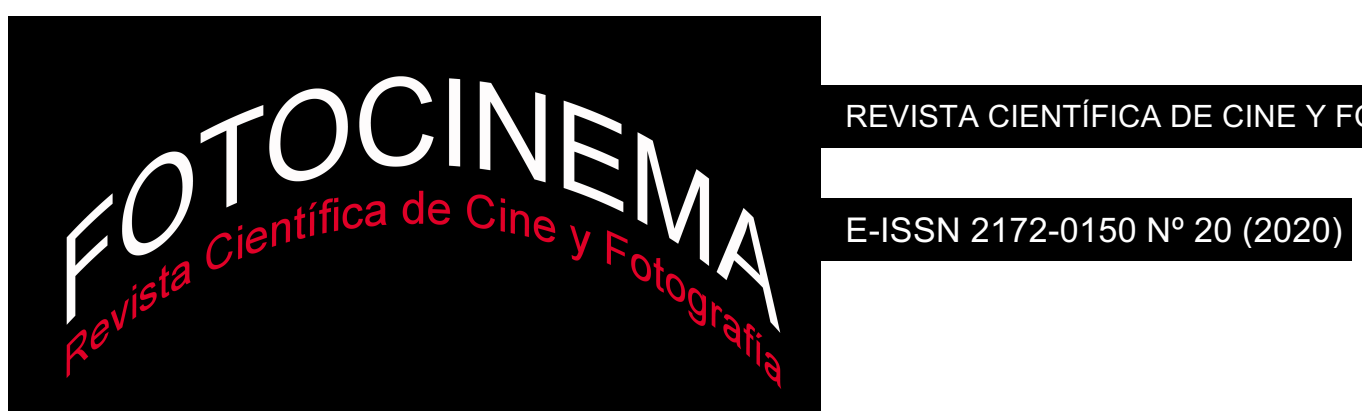

\title{
La articulación de la memoria histórica en Drawings for projection, de William Kentridge
}

\section{The articulation of historical memory in Drawings for projection by William Kentridge}

\author{
Cristina Manzano Espinosa \\ Universidad Complutense de Madrid, España \\ cristina.manzano@ccinf.ucm.es
}

\section{Resumen}

La consideración de la serie de animación Drawings for Projection (William Kentridge, 1989-2011) como una reflexión incisiva sobre el concepto de memoria histórica, se sistematiza en este artículo en el estudio de distintos aspectos creativos. La técnica artística, el lenguaje cinematográfico, la traducción de la identidad de autor a sus dos principales personajes y la relación de elementos representativos de la memoria histórica, colectiva e individual tienen como objetivo explorar la representación del recuerdo del Apartheid sudafricano y su terminación, de forma paralela a las sesiones de la Comisión para la Verdad y la Reconciliación. El hecho de que la serie estuviera compuesta en un principio por nueve títulos y en 2011 Kentridge produjese un décimo para valorar los cambios en el proceso, expone la complejidad de concluir cualquier esfuerzo de rescate del pasado.

\begin{abstract}
The consideration of the animation series Drawings for Projection (William Kentridge, 1989-2011) as an incisive reflection on the concept of historical memory is systematized in this article from various creative aspects. Artistic techniques, film language and the reflection of the author's identity into the two main characters aim to explore the reminder of South African Apartheid and its termination, in parallel with the sessions of the Truth and Reconciliation Commission. Representative elements of historical, collective and individual memory in the series also allow to asses changes in the process, regarding that the series were originally composed by nine titles to which Kentridge added a tenth in 2011.
\end{abstract}

Palabras clave: Memoria histórica; Animación; Drawings for Projection; William Kentridge, Sudáfrica, Apartheid.

Keywords: Historical memory; Animation film; Drawings for Projection; William Kentridge; South Africa; Apartheid. 


\section{Introducción}

En 2017, William Kentridge (Johanesburgo, 1955) recibe el premio Princesa de Asturias de las Artes por su compromiso artístico y sociopolítico con el contexto contemporáneo (Molina, 2017). En agosto de 2019, Sudáfrica prohíbe la exhibición de la bandera del Apartheid, veinticinco años después de la finalización del régimen, por constituir apoyo a un discurso de odio (Head, 2019). Estos dos hechos proporcionan un marco contemporáneo al estudio que abordamos sobre la serie de cortometrajes de animación Drawings for Projection ${ }^{1}$ (1989-2011). En ella Kentridge reflexiona sobre el Apartheid $^{2}$, el final del periodo y sus posteriores consecuencias, atendiendo al planteamiento de Gobby (2018) sobre la revisión histórica, que propone deconstruir el ideal heroico sacando a la luz los aspectos del pasado que fueron ignorados o suprimidos.

Los conceptos de memoria histórica (Ruiz Vargas, 2008; Cubitt, 2008; Nora, 1989) y memoria colectiva (Halbwachs, 2002) aplicados a la evolución de Sudáfrica y el de memoria personal (Hochberg, 2014), que ilustra cómo Kentridge busca su posición en una sociedad dividida, se mezclan en la serie con la peripecia narrativa de un poderoso magnate y los personajes que le rodean.

Kentridge elige como medio de expresión el cortometraje de animación, formato idóneo para conectar al espectador con los problemas contemporáneos, ya que posee "el potencial de alcanzar públicos de un modo que el cine de acción real no puede por razones subjetivas, culturales o técnicas" (Selby, 2013, p.7). Kentridge escoge la estética artesanal frente a la producción industrial, en un proceso creativo que relaciona la técnica con el

\footnotetext{
${ }^{1}$ La serie estaba compuesta en un principio por los primeros nueve títulos que aquí estudiamos. En 2011, Kentridge añadió un 'decimo título, Other Faces. En 2015, el hermano del autor, Matthew Kentridge, publicó un libro que recogía las diez piezas bajo el título The Soho Chronicles: 10 Films by William Kentridge, hablando principalmente del proceso creativo. Hemos conservado en este estudio el título Drawings for Projection, considerando que es el título con el que se conoce la serie.

2 Apartheid es el término que califica a la segregación racial que tuvo lugar en Sudáfrica desde 1948 hasta 1991. Ese año aparecería una legislación contraria que culminaría en 1994 con la elección de Nelson Mandela como presidente (Davenport \& Saunders, 2000).
} 
contenido del mensaje, aplicando la reflexión de Wells: "La animación, especialmente cuando emplea métodos alternativos, suele basarse en una sensibilidad filosófica (...) que utiliza el medio para encarnar una imagen o visión determinadas" (2007, p.152). La originalidad del planteamiento de Kentridge en relación a la memoria histórica reside en prescindir del recuento de hechos y pasar a comunicarse directamente con el espectador en el ámbito artístico y de la reflexión, compartiendo con Zemon Davies la idea del cine "como pensamiento experimental sobre el pasado" (Goyeneche, 2012, p.390).

En este contexto pretendemos exponer la capacidad de Kentridge para crear una reflexión sobre los acontecimientos contemporáneos, al tiempo que los va convirtiendo en un discurso sobre la memoria histórica, individual y colectiva. Este enfoque aporta una nueva perspectiva a una serie de animación cuyo desarrollo abarca más de dos décadas de reflexión sobre los problemas interraciales en Sudáfrica, complementando los estudios ya existentes sobre la obra de Kentridge.

\section{Marco teórico y metodología}

El análisis de Van Caelenberge (2008) sobre Drawings for Projection establece que existen dos periodos diferenciados en la implicación de Kentridge con los sucesos históricos: antes de 1995, se posicionaría junto a los trabajadores represaliados, derivando después su discurso hacia una perspectiva más reflexiva: "After the 1995 installation of the debated Truth and Reconciliation Commission, his Ubu Project stresses the difficulty of judgement"3 (Van Caelenberge, 2008, p.2). En este sentido su investigación se relaciona con la consideración del concepto de liminalidad en el arte contemporáneo propuesta por Westerveld, quien sitúa a Kentridge en una posición intermedia y ambigua ante los acontecimientos que refleja: "setting himself appart from the given social system and the behaviour of role-playing

\footnotetext{
3 "Tras la instalación, en 1995, de la controvertida Comisión para la Verdad y la Reconciliación, su proyecto sobre Ubu se centra en la dificultad de juzgar". Traducción propia.
} 
members who enforced the system, Kentridge places himself in a state of outsiderhood"4 (2010, p. 118).

Aunque Maltz-Leca (2014) centra su trabajo en el corto experimental Shadow Procession (1999), que no pertenece a la serie que analizamos, su enfoque se acerca a nuestra investigación al equiparar la reestructuración política con el propio proceso de producción de la obra. Como veremos, en Drawings for Projection también hay una voluntad de relacionar el proceso creativo con el discurso. Gomes (2012) cataloga la producción de Kentridge indagando en las interacciones entre el dibujo y la imagen en movimiento, a partir de un inventario de las tecnologías utilizadas por el autor en sus animaciones. Para nosotros, la técnica de Kentridge proporciona un ejercicio de fragmentación y aparente ruptura de sentido destinado a buscar un discurso más allá de la ficción.

La relación de la reflexión histórica con la experiencia personal ha dado lugar a estudios como el de Thomson y Laubscher (2006), que examinan la serie desde una perspectiva psicológica, señalando la capacidad sanadora de la creatividad a través del discurso cultural. Este enfoque también es seguido por Karam (2017), quien se centra en la pieza Felix in Exile, analizando el concepto de postmemoria como una forma de tratar con el trauma posterior a los acontecimientos históricos.

Entre los estudios sobre memoria colectiva, tomamos como punto de partida el enfoque de Halbwachs sobre la importancia de los recuerdos colectivos que "nos son traídos a la memoria por otra persona, aun cuando se trate de hechos que nos han ocurrido solo a nosotros y de objetos que únicamente nosotros hemos visto" (2002, p.4), ya que consideramos que Drawings for Projection tiene esa incidencia, aunque no mencione hechos históricos concretos. Es importante también incorporar la reflexión, como señala Olick (2013), de que las construcciones narrativas de la memoria no son ya territorio exclusivo de historiadores, sociólogos o teóricos de la cultura, sino que se han convertido en un territorio de interés para la cultura popular.

4 "Tras situarse voluntariamente apartado del sistema social dado y del comportamiento de los implicados en el refuerzo del sistema, Kentridge asume una posición de alejamiento". Traducción propia. 
Para poder evaluar el alcance de la implicación de la serie de Kentridge con el concepto de memoria histórica hemos tenido también en cuenta las reflexiones de Ruiz Vargas (2008), quien examina el concepto desde la perspectiva de la psicología cognitiva, concluyendo que los términos de memoria histórica o memoria colectiva no tienen base epistemológica, aunque su labor social, moral y política son necesarias como ejercicio reparador y de búsqueda de la verdad. Rieff aborda esa idea con mayor escepticismo, incidiendo en el hecho de la separación de distintas memorias históricas ante un mismo acontecimiento: "Historically, it is only when there is no clear winner that both sides may be able to sustain their own incompatible memories"5 (Rieff, 2016, p.12).

Finalmente, para reseñar el desarrollo del Apartheid y su posterior proceso de finalización hemos acudido a los textos de Clark y Worger (2013) y Davenport y Saunders (2000), que proporcionan una visión completa sobre las intenciones, contradicciones y evolución de Sudáfrica desde los años cuarenta hasta nuestros días.

Las diez piezas que forman la serie y que aquí analizamos son: Johannesburg, 2nd Greatest City after Paris (1989), Monument (1990), Mine (1991), Sobriety, Obesity and Growing Old (1991), Felix in Exile (1994), History of the Main Complaint (1996), Weighing and Wanting (1997), Stereoscope (1999), Tide Table (2003) y Other Faces (2011).

Para abordar su estudio nos serviremos del análisis de contenido utilizando referencias historiográficas y del análisis textual basado en el propio lenguaje cinematográfico y artístico. Con este enfoque pretendemos resolver los objetivos de la investigación. El primero, mostrar la relación existente entre la expresión artística y la gestión del recuerdo, ya que consideramos que en esta obra la forma no es una herramienta al servicio del discurso, sino que forma parte del discurso mismo. Y el segundo, identificar en la serie los elementos narrativos que hablan de la memoria histórica y la memoria colectiva, incluyendo la propia identidad del autor.

5 "Históricamente, solo cuando no hay un claro vencedor, ambas partes pueden sostener sus propios recuerdos incompatibles". Traducción propia. 
Este análisis se centra, pues, en tres aspectos: qué elementos del texto y del discurso son productores de significado en relación con la memoria histórica; cómo refleja la técnica artística ese concepto y cómo deposita Kentridge su propia identidad en la serie. Para nosotros, en estos tres aspectos reside la valoración que Kentridge lleva a cabo sobre el concepto de memoria histórica.

\section{Identidad nacional, identidad personal}

Kentridge comienza su serie el año en que el presidente sudafricano Pieter Willem Botha es sustituido por Frederick Willem de Klerk (Clark \& Worger, 2013). Johannesburg, 2nd Greatest City after Paris aparece, pues, en 1989 inaugurando un nuevo periodo para la historia del país. Un año después, en 1990, Nelson Mandela es liberado y Kentridge estrena Monument. Ni ese título ni el siguiente, Mine (1991), hacen alusión al hecho. Kentridge no sigue la cronología del Apartheid, ni se refiere directamente a los cambios políticos de país, sino que se centra en el impacto sobre los ciudadanos. A Mine le sigue Sobriety, Obesity and Growing Old (1991) y un año después de que Mandela sea elegido presidente (1993), Kentridge dirige Felix in Exile, calificada por Karam (2017) como el ejemplo de la postmemoria (Hirsch, 2012). El artista se relacionaría con este concepto en los términos que describe Karam, explicando la relación entre un individuo o una comunidad con un trauma cultural o colectivo, "which is not strictly based on a direct, familial connection. It is defined through identifying with the victim"6 (Karam, 2017, p.5). En este episodio además se inicia un aparente proceso de cambio para el personaje del magnate. El propio Kentridge expone su significado: "It questioned the way in which the people who had died on the journey to this new dispensation would be remembered"7 (Cameron et al., 2010, p.90). El siguiente título, History of the Main Complaint, coincide con el comienzo de las audiencias de la Comisión para la Verdad y la

\footnotetext{
6 "que no se basa estrictamente en una conexión directa y familiar. Se define a través de la identificación con la víctima”. Traducción propia.

7 "cuestionaba el modo en que las personas que habían muerto en este viaje hacia una nueva administración serían recordadas”. Traducción propia.
} 
Reconciliación, proceso señalado por Davenport y Saunders (2000) como un modo de encauzar indemnizaciones y esclarecer crímenes. Aquí, el magnate Soho Eckstein yace en coma recordando su intervención en el curso del país (F1). Es la conexión más directa entre los hechos históricos y la ficción creada por Kentridge. Como explica Godfrey: "In the films Felix in Exile (1994) and History of the Main Complaint (1996) Soho and Felix, like Kentridge, are seen reflecting on their private questions about guilt and responsibility as well as those in the public realm"8 (2014, p.10).

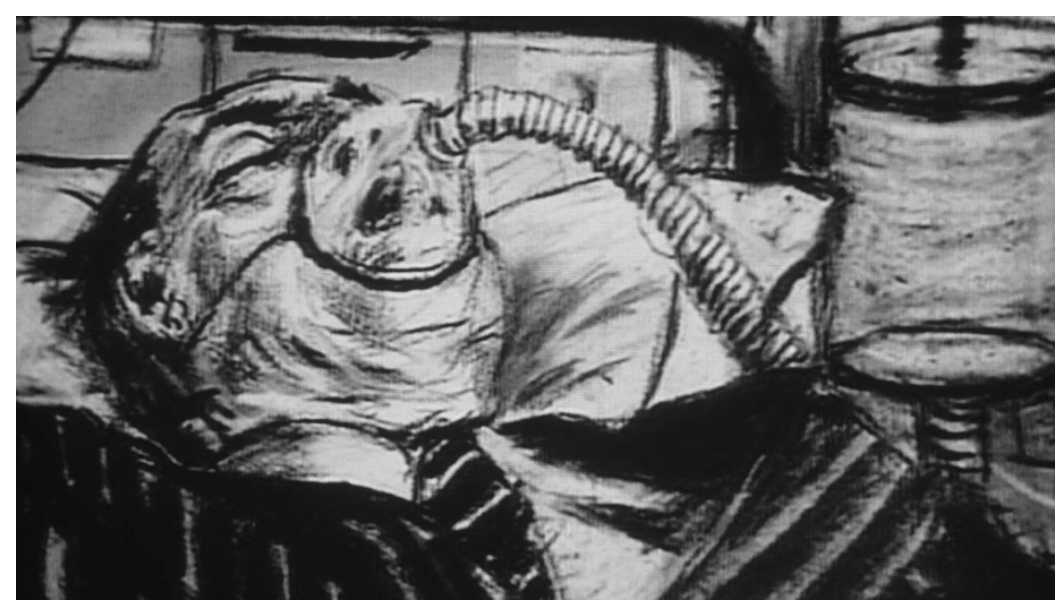

F1. History of the Main Complaint (1996), William Kentridge. Fotograma de la película

El proceso de reflexión para Soho se intensifica en el siguiente título, Weighing and Wanting (1997), cuando en Sudáfrica ya ha entrado en vigor la Constitución aprobada bajo el mandato de Nelson Mandela. Kentridge introduce en la pieza un rótulo que pide: "Give Forgive"9. Sudáfrica sigue su proceso de renovación y Kentridge dirige en 1999, Stereoscope. Ahora que la figura de Felix no está para hacer contrapunto con Soho, este se desdobla y asume distintas posibilidades de cambio. Sin abandonar el foco sobre el pueblo africano, Kentridge desciende la importancia de su personaje principal para dedicarle una pieza de la serie a la enfermedad del SIDA: Tide Table (2003) habla de la parte de la población a la que afectan todas las lacras, mientras la élite observa de lejos. La culminación de la serie, con

\footnotetext{
8 "En las películas Felix in Exile (1994) y History of the Main Complaint (1996) Soho y Felix, como Kentridge, aparecen reflexionando tanto sobre sus cuestiones privadas acerca de la culpa y la responsabilidad, como sobre las cuestiones de ámbito público." Con respecto a la grafía de Felix, conservaremos en el artículo el nombre como en el original, sin tilde.

9 “Da el perdón”. Traducción propia.
} 
Other Faces (2011) muestra a un Soho que a pesar de todas sus circunstancias vitales no ha cambiado y a esas otras caras a las que hace alusión el título, que no han solucionado sus problemas. Kentridge (2016) sopesa los hechos y concluye que las acciones de la Comisión fueron provisionales y no dieron cierre a una sociedad en donde incluso hoy existe un sentimiento de inestabilidad. Su serie intenta superar la afirmación de Halbwachs: "cada memoria individual es un punto de vista sobre la memoria colectiva" (2002, p.5), convirtiendo recuerdos e información en una visión única. En marzo de 1960 tiene lugar la matanza de Shaperville, cuando la policía abre fuego sobre los manifestantes que protestaban contra el Apartheid. Kentridge, con cinco años, ve en el despacho de su padre, abogado, las imágenes de los fallecidos. Años después reconocerá que algunos episodios de la serie servirían para lidiar con ello: "I would say that although when I was drawing the bodies for Felix in Exile I did not have the Shaperville massacre in mind (...) I'm sure that, in a sense, it was trying to tame that horror of seeing those images." (Sittenfeld, 2001, p.10).

La infancia y la juventud de Kentridge suceden durante los años del Apartheid en los que las relaciones internacionales de Sudáfrica se van deteriorando: “A medida que más y más países se distanciaban del gobierno nacionalista de Sudáfrica (...) se redujo la lista de países que podían visitarse con un pasaporte sudafricano" (Kentridge 2018, p.89). Kentridge decide ir a estudiar a París a comienzos de los 80 y este alejamiento le creará una serie de sentimientos encontrados, que irá resolviendo a lo largo de su obra. Kentridge diseña dos personajes principales que recogen la dualidad sudafricana: Soho Eckstein, quien encarna al capitalismo y al colonialismo y Felix Teittlebaum, su némesis, que tiene una relación amorosa con la mujer de Eckstein. Ambos personajes son la configuración de la máscara que señala Gombrich: "Por lo general aceptamos la máscara antes de advertir la cara. La máscara representa en este caso (...) las desviaciones de la norma que distinguen a una persona de las demás" (2014, p.26). Entre los dos recogen la división que siente el propio Kentridge al pertenecer por nacimiento a la clase dominante, pero al mismo tiempo sentirse obligado a reflejar la injusticia. 
Desde Johannesburg, 2nd Greatest City after Paris hasta Other Faces, Eckstein sigue esta línea de desarrollo: definición como magnate, representante de la clase dominante, explotador de los trabajadores y de la tierra, detentor de la maquinaria económica, imagen de la decadencia, solicitante del perdón, penitente $\mathrm{y}$, finalmente, reconocedor de su imposibilidad de adaptación.

La línea de desarrollo del personaje de Felix con respecto al discurso está centrada en la figura del observador. Está diseñado para trasladar al texto las ideas de redención, cambio, espejo y reconciliación. Pero sobre todo Felix representa la necesidad que tiene Kentridge de un discurso añadido sobre las acciones de Soho. Sobriety, Obesity and Growing Old comienza con un rótulo que dice: "Felix listens to the world"10. Felix encarna a la parte de la Sudáfrica dominante que puede redimirse. Aunque físicamente Felix está más cercano a la fisonomía de Kentridge y a su presente, Soho es el personaje donde refleja su memoria individual. Kentridge opta por el segundo tipo de relación entre historia y memoria que propone Cubitt (2008) en el que es el presente el que produce el pasado a través de la reflexión y el análisis. A partir de Felix in Exile, Soho se va haciendo más importante hasta el punto de que Felix desaparece. En las últimas piezas, el retrato de Kentridge aparece nítido en el rostro de Soho.

Para narrar la evolución de sus dos personajes principales dentro de la ficción, Kentridge acepta en parte el arquetipo tal y como Vogler lo define: "Ancient patterns of personality that are the shared heritage of the human race"11 (2007, p.23). Estos personajes están, además, al servicio de un subtexto conectado a la memoria histórica e individual, entendidas como representación del pasado a un cierto nivel cultural (Cubitt, 2008). Kentridge utiliza algunas etapas del viaje del héroe que Vogler (2007) describe, siendo especialmente obvias La aproximación a la caverna más profunda, La Odisea y El camino de regreso ${ }^{12}$. En su propuesta de revisión histórica el

\footnotetext{
10 "Felix escucha al mundo". Traducción propia.

11 "Antiguos modelos de personalidad que son la herencia compartida de la raza humana". Traducción propia.

12 Aunque este no es el tema principal del estudio es interesante que una reflexión histórica que roza en ocasiones el ensayo, mantenga también los estadios de la narración que
} 
discurso se convierte en un extracto del viaje cuya función es llamar a la reflexión: "Kentridge has spoken of the spectrum of 'white guilt' in South Africa. There are those, he says, who refuse to feel guilt, and those who are destroyed by it. Then there are those in between, like him, whose intelligence is shaped by its presence"13 (Godfrey, 2014, p.10). Kentridge apela a una resolución en el mundo real, pero no dentro del relato.

\section{4.- La técnica es el mensaje}

Sin storyboard previo y partiendo de un dibujo a gran escala realizado en carboncillo y pastel, Kentridge va borrando y añadiendo modificaciones que fotografía una a una en película de $16 \mathrm{~mm}$. (Hecker \& Kentridge, 2010). Los borrados continuos sobre el mismo soporte dejan una huella, que muestra al espectador los distintos estadios del dibujo, y relaciona la ausencia de las figuras y su rastro sobre el papel con la reflexión que el artista hace sobre los damnificados por el Apartheid: "the film often evokes pathos through their imagery techniques such as imperfect erasure"14 (Christov-Bakargiev, 2017, p.3).

Aunque algunas piezas de la serie cuentan también con imágenes creadas a partir del grabado (punta seca y aguatinta), como las de Felix in Exile (Hecker \& Kentridge, 2010), es el proceso de dibujo y borrado el que mejor

establece Vogler. Más aún por cuanto que con esa estructura está hablando no sólo de dos personajes de ficción, sino de la propia historia sudafricana. La aproximación a la caverna más profunda (Approach to the Inmost Cave) es el momento del viaje del héroe en que éste se prepara para enfrentarse a la prueba más dura (Vogler, 2007, 143): el propio proceso del Apartheid para Sudáfrica y la explotación para Soho. La Odisea (The Ordeal) es la prueba central para el héroe, quien superándola habrá traspasado el momento de crisis $(2007,155)$. Se traduce para Sudáfrica en el proceso abierto por la Comisión para la Verdad y la Reconciliación y para Soho la revisión de sus actos que tiene lugar a través de Weighing and Wnting y History of the Main Complaint. Finalmente, El camino de regreso (The Road Back) es el momento en que el héroe toma la decisión de continuar el camino o retornar al punto de regreso $(2007,187)$. Desde la perspectiva de Kentridge en la serie, Sudáfrica no ha vuelto al punto de partida, pero el camino recorrido no se ha completado y transcurre lento. En la serie esto se refleja con el paisaje florecido, pero Soho reticente a aprender de sus errores.

${ }_{13}$ "Kentridge ha hablado del espectro de la culpa blanca en Sudáfrica. Están aquellos, dice, que rehúsan sentir culpa. Y aquellos que están destruidos por ella. Después están los que se sitúan en el medio, como él, cuya inteligencia esta modelada por esa culpa." Traducción propia.

${ }_{14}$ "La película evoca a menudo el pathos a través de técnicas metafóricas como el borrado imperfecto". Traducción propia. 
representa los conceptos de memoria e historia, ya que refleja la relación entre el contenido y el paso del tiempo: "La sustancia invisible del tiempo es convertida en el material de la película. La cinta no solo contiene el tiempo, sino que lo calibra” (Kentridge, 2018, p. 133). La consideración que el artista tiene de la relación entre el proceso y el tiempo establece la base para hablar de en qué medida los trazos borrados, el rastro del dibujo o simplemente lo que no se dibuja, se convierten en una metáfora de los acontecimientos históricos: "La película graba la modificación y también el fantasma de la historia de esa modificación. Y así quedan integrados en la cámara.” (Kentridge, 2018, p. 139). El dibujo y su ausencia contribuyen así a convertir la materia fílmica en un palimpsesto (Dubow \& Rosengarten, 2004). En Monument, la estatua conmemorativa del trabajador se ve liberada de su rigidez y se aleja por un paisaje desolado portando su pesado fardo. El proceso de dibujo y borrado deja en el paisaje el rastro del personaje señalando la imposibilidad de borrar el pasado. En Tide Table, la construcción y desconstrucción de la imagen se recoge a través del periódico y el mar, ambos en continua transformación. El mundo cambia y pasa a la memoria colectiva a través de las noticias. El borrado y escritura de las olas y las mareas que dan título al cortometraje se convierten en la imagen especular del periódico: ambos reflejan sucesos cíclicos, ambos están en continuo movimiento y a pesar de conservar su materia, no hay dos momentos (dos dibujos) iguales. Other Faces tiene también una estrecha relación entre la técnica y el discurso. La discusión entre Soho y el hombre negro se articula de forma muy fragmentada, no sólo por el montaje, sino por la intervención gráfica de los trazos de Kentridge, que son recurrentes e imitan el barrido de la cámara.

Pero el ejercicio de borrado y reescritura no solo es llevado a cabo a través de la técnica. En Johannesburg, 2nd Greatest City after Paris Soho modifica el paisaje, pasa las páginas del libro de la orografía escribiendo, literalmente, la historia de Johannesburgo. También intenta borrar a Felix con un movimiento de su brazo. Ese gesto aparece de nuevo en Mine, cuando Soho aparta todo lo que hay encima de su mesa para hacer espacio al pequeño rinoceronte, cuyo significado veremos más adelante. Kentridge opta, pues, 
por la posibilidad que tiene el dibujo de dejar constancia del proceso de trabajo a través de modificaciones (Cabezas, 1999), el borrado imperfecto como recomendación de no olvidar el pasado.

La elección del cortometraje de animación como medio de expresión implica trasladar a la ejecución manual el propio lenguaje cinematográfico, reflexionando sobre la importancia de cada elección formal: "He recalls how drawing is a hermeneutic advance upon photography's mode of representation, just as history writing is a hermeneutic advance upon the random details of mere chroniclism"15 (Stewart, 2005, p. 52). Las piezas de la serie conectan con el cine mudo introduciendo rótulos con una función semejante a los intertítulos: guiar al espectador y reflexionar sobre los acontecimientos. La pieza más profusa en rótulos es la primera, Johannesburg, 2nd Greatest City after Paris, en la que aparecen diez mensajes, incluido el título y en la que podemos señalar como los más significativos relacionados con el concepto de memoria histórica: "Felix, captive of the city", "Soho Eckstein takes the world", "Rumors of a different life" y "Soho feeds the poor"16. Los dos primeros fijan la posición dual en la que se divide el propio Kentridge a través de sus dos protagonistas, representando también a una ciudad dividida. Los otros dos aparecen en clara disonancia con las imágenes que muestran. Este discurso de contradicciones se ve reforzado con el que aparece en Monument: "Soho Eckstein, civic benefactor"17, como reflejo de la crítica a la memoria colectiva y al mensaje único. Soho no sólo ha participado de esa explotación en el pasado, sino que intenta beneficiar su imagen a través del homenaje. La clase dominante no reflexiona sobre el pasado de forma autocrítica, sino que lo valida, como si siempre viviera en las cercanías del hecho: “The recent past is the hardest to know and understand"18 (Judt, 2008, p.12). En este sentido, Rieff señala la importancia para los historiadores de la construcción,

\footnotetext{
15 "Señala el dibujo como un avance hermenéutico sobre el modo de representación de la fotografía, así como la escritura de la historia es un avance hermenéutico sobre los detalles aleatorios que ofrece la crónica”. Traducción propia.

16 "Felix, cautivo de la ciudad", "Soho Eckstein se apodera del mundo", "Rumores de una vida diferente" y "Soho alimenta a los pobres". Traducción propia.

17 "Soho Eckstein benefactor cívico". Traducción propia.

18 "El pasado reciente es el más difícil de conocer y comprender". Traducción propia.
} 
imaginación o manufactura del recuerdo histórico, puesto que los mitos y leyendas pueden ser "tan potentes como la realidad, si es que se ajustan a las expectativas sociales en un momento dado" (2016, p.12).

Los rótulos en Sobriety, Obesity and Growing Old están dedicados a la caída del magnate y a la separación de su mujer: "To recapitulate”19 hace alusión a la relación rota ente Soho y su mujer y podemos también considerarlo como una alusión al proceso de sanación del país. A medida que avanzan los episodios, Kentridge pierde la necesidad de ese refuerzo textual, renunciando a la clausura del discurso. Aun así, todavía podemos encontrar algunos mensajes significativos. En Weighing and Wanting, Soho se encuentra solo en su salón, viendo como las torretas de comunicación se dibujan en su pared. El rótulo "In whose lap I lie" 20 incide en la idea de que Soho ha renunciado a su mujer para yacer en el regazo de los negocios. En el episodio se atisba una vida en la que Soho podría haber vivido en armonía con su mujer y consigo mismo, apuntando una alternativa al desarrollo del Apartheid.

En Other Faces, que es la última pieza de la serie y sirve para valorar si el proceso de sanación ha dado resultados, el texto vuelve a ser importante. Un cartel de anuncios convertido en pantalla de cine se proyectan imágenes del pasado: "That Which is not Drawn”, "Healing to All in Global”21, una alusión directa al proceso de restauración de la memoria histórica de la Comisión. El rótulo "Drawn Overdrawn" 22 no es solamente la descripción de su método de trabajo, sino también la visión que Kentridge tiene de un proceso histórico que parece ser recurrente.

A medida que los rótulos van perdiendo importancia en la serie, Kentridge redobla el esfuerzo del lenguaje cinematográfico, afianzando la idea de Caparrós (2007) de que el cine contribuye a analizar las conexiones entre el imaginario colectivo y la realidad de una sociedad. La apertura y cierre del diafragma estructuran el discurso asociando ideas (pasando de Felix en la

\footnotetext{
19 "Recapitular". Traducción propia.

20 "En cuyo regazo yazgo". Traducción propia.

21 "Lo que no está escrito", "Sanando a todos en conjunto". Traducción propia.

22 "Dibujado sobredibujado". Traducción propia.
} 
bañera, con sus fantasías sexuales sobre la señora Eckstein a la pelea metafórica de Soho y Felix), estableciendo elipsis temporales (en Sobriety, Obesity and Growing Old el cierre de diafragma introduce la prolepsis en la que la Sra. Eckstein vuelve a su marido) o acotando el episodio (finalización de Johannesburg, 2nd Greatest City after Paris y comienzo en Monument, que es el episodio siguiente).

Pero lo más significativo es sin duda la evolución y sofisticación del montaje. Los episodios más llamativos a este respeto son: Mine, Sobriety, Stereoscope y Other Faces. En Mine Kentridge aprovecha la metamorfosis como estrategia creativa e indicador de las relaciones causa-efecto. El émbolo de la cafetera de Soho se introduce en la tierra y dirige al espectador hacia todo el entramado de la explotación minera. Sobriety, Obesity and Growing Old es quizá la pieza más fragmentada en cuanto a planificación. La fragmentación de los cuerpos, multiplicación de las posibilidades de la angulación, del tallaje de planos y del montaje paralelo ofrecen una descomposición continua de la imagen en la que puede verse la similitud con las distintas facetas de los acontecimientos del país. Soho quiere recuperar a su mujer igual que Sudáfrica querrá volver a colocar sus piezas de una forma aceptable y lógica, buscando así un reconocimiento exterior. Kentridge dirige este corto en pleno proceso de abolición del Apartheid²3.

Stereoscope es un punto de inflexión en la sofisticación del montaje. Las disyunciones espaciales, la planificación, los movimientos de cámara y el ensamblaje de planos hacen alusión no sólo al recordatorio de la violencia en Sudáfrica, sino a sucesos contemporáneos en otros lugares del mundo. Se incide en la idea de que los acontecimientos de la memoria histórica tienden a repetirse, aunque no sea en el mismo lugar. Tal como Dancer (2016) recoge de una entrevista previa realizada para One People, Kentridge reconoce que las imágenes de Stereoscope, aunque ambientadas en Johanesburgo, fueron inspiradas por sucesos en Yakarta, Moscú, o Kinshasa, que aparecían en los periódicos o en televisión. Otros autores, como Rosenthal (2010), han

${ }^{23}$ El Apartheid se instauró en el país en 1948 y entre 1990 y 1993 se pusieron en marcha una serie de acciones y leyes para acabar con el periodo, incluida la liberación de Nelson Mandela el 11 de febrero de 1990, tras 27 años de cautiverio (Clark \& Worger, 2013). 
señalado que, aunque la materia de estudio de la serie es el contexto sudafricano, su temática refleja la injusticia social allá donde se produzca. Podemos ampliar este alcance no solo a distintos espacios, sino también a distintas épocas. En Johannesburg, 2nd Greatest City after Paris, Felix pelea con Soho en una imagen que remite a Duelo a garrotazos (1820-1823), la obra de Francisco de Goya, que simboliza el conflicto entre las dos Españas de la época (Trienio Liberal), progresistas y moderados y que Kentridge traslada a su obra (F2) a modo de espejo del conflicto sudafricano y muy posiblemente como imagen de su propia dualidad.

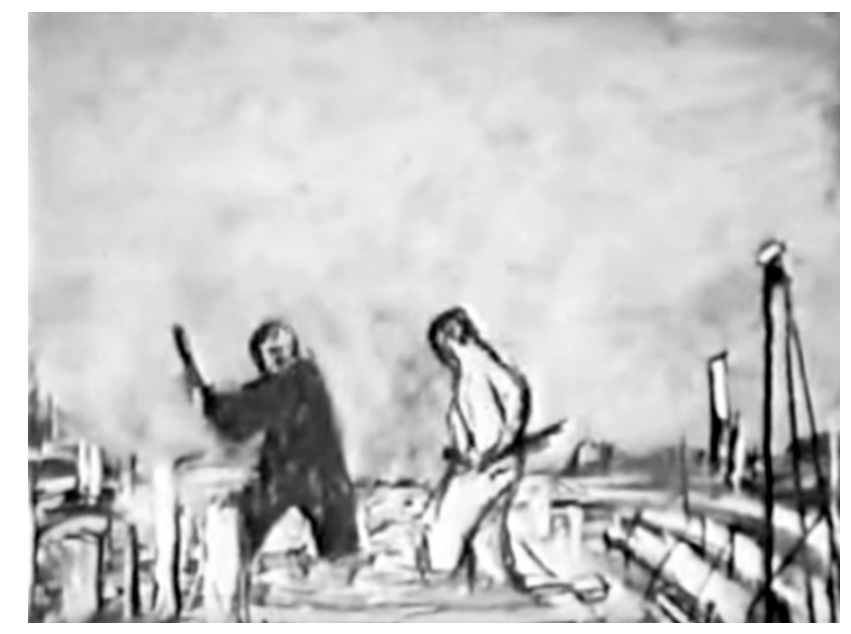

F2. Johannesburg, 2nd Greatest City after Paris (1989), William Kentridge. Fotograma de la película.

Other Faces utiliza el montaje, los barridos y la articulación del raccord para ubicar en la pantalla dos posiciones: la izquierda para Soho y la derecha para el hombre africano contra el que ha tenido el accidente. Esta división de posiciones, aparece por primera vez en Johannesburg, 2nd Greatest City after Paris para establecer la dualidad riqueza/pobreza y en Stereoscope, para enfrentarse a sí mismo, en ese desdoble antes mencionado.

Es necesario también señalar que como parte de la estética de su obra Kentridge utiliza el elemento sonoro para reclamar el foco de atención sobre el significado de las imágenes. A pesar de prescindir de los diálogos, el sonido de las piezas ofrece un universo complementario tanto de efectos sonoros como de música. La importancia del discurso sonoro de Johnannesburg, 2nd Greatest City after Paris, está basada en la combinación de la banda sonora 
(que aquí emplea la música de Duke Ellington y las voces del South Kaserne Choir) con el sonido producido por la vida de los objetos, como la máquina de escribir o el agua, que serán habituales en la serie. En Drawings for Projection conviven la música clásica occidental, como influencia y parte del interés artístico de Kentridge y compositores sudafricanos, cuya presencia contribuye a la valoración de la propia cultura en el registro de la memoria. El Concierto para chelo en Si menor, de Dvorák, editado junto al sonido opresivo de las taladradoras en Mine; el Cuarteto para cuerda del mismo compositor, que aparece en Sobriety, Obesity and Growing Old o el Madrigal de Monteverdi que ilustra el estado inconsciente de Soho durante History of the Main Complaint) se alternan con la colaboración asidua de los músicos sudafricanos Phillip Miller y Motsumi Makhene, que convierten Felix in Exile en una de las piezas más sugerentes a través de la voz de Sibongile Khumalo, cuya canción modela el personaje de Nandi. Es especialmente significativa la inclusión del músico congoleño Franco en la banda sonora de Tides Table. Franco había fallecido a causa del SIDA, por lo que la temática de la pieza incluye también un homenaje concreto.

\section{5- Elementos de producción de significado en torno a la memoria histórica}

Kentridge resuelve el subtexto de Drawing for Projection manteniendo un equilibrio entre la función del creador y la del historiador: si la narración necesita tanto el conflicto como el planteamiento, nudo y desenlace para avanzar, el historiador "sabe que la vida sigue, que no tiene desenlaces. Como mucho, hay conclusiones, que son una reflexión sobre los motivos que explican un suceso o un proceso”. (Montero \& Paz, 2012, p.166). A lo largo de la serie aparece un conjunto de elementos que se repiten propiciando la continuidad discursiva. El paisaje, el agua, los objetos y su transformación, los personajes y los animales conforman un discurso en torno a tres aspectos de la historia de Sudáfrica: la política del Apartheid, los desequilibrios sociales y el abuso del capitalismo colonial. 


\subsection{El paisaje}

Johannesburgo, desolada en el ámbito rural y agresiva en el urbano, es un paisaje postindustrial y postcolonial en donde se han explotado tanto los recursos humanos como los naturales (Labuscagne, 2007). Alberga signos de intervención: líneas azules y círculos rojos que ejercen una función fática y elementos significativos como la tierra yerma, con postes, piedras y vallas publicitarias.

Desde el primer título, la valla publicitaria (F3) le sirve a Kentridge para referirse a la creación de la memoria colectiva, también apoyada por otros elementos del paisaje como los altavoces y los postes eléctricos por los que circula la comunicación.

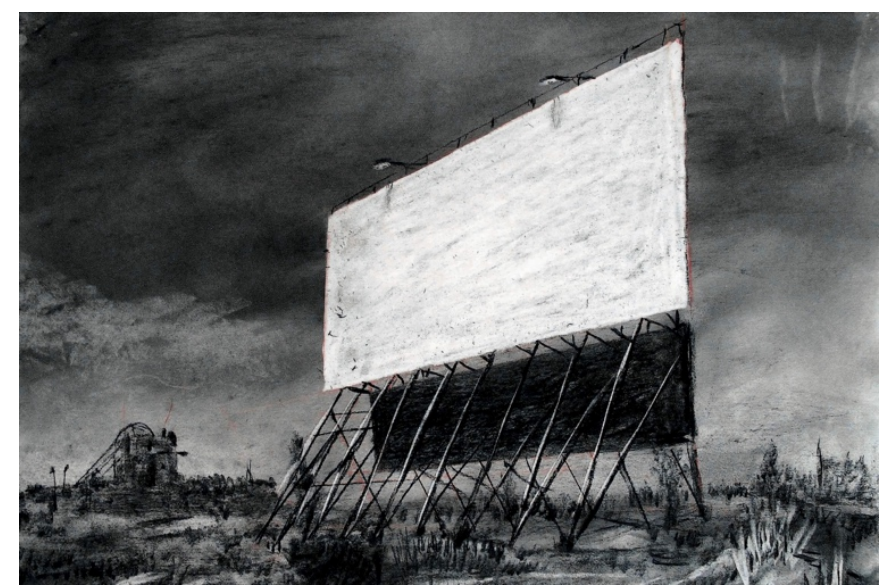

F3. Other Faces (2011), William Kentridge. Fotograma de la película

El paisaje es el resultado de la actividad desplegada por la élite económica y social poseedora de la tierra (Opperman, 2012), tal y como se relata en Johannesburg, 2nd Greatest City after Paris. En Monument, en el paisaje vacío se coloca la estatua que conmemora la esclavitud; en Mine, muestra la explotación geológica; en Felix in Exile, el paisaje se cartografía incluyendo en él las muertes enterradas con el tiempo. En el último episodio, Other Faces, el paisaje aparece florecido y con vegetación, como alusión a la renovación (posible quizá gracias a toda el agua vertida en todos los episodios anteriores). Es también en este episodio cuando caen los postes que habían estado presentes durante toda la serie. Los postes caídos y los montículos desaparecidos indican la memoria de la propia serie (los 
montículos fueron generados por la tierra extraída de las minas), haciendo alusión a los cambios sociales y políticos.

La ciudad aparece en pocas ocasiones y es un elemento poco acogedor. Un conjunto de edificios destinado a albergar a los trabajadores es la referencia gráfica a los guetos, al barrio de Soweto ${ }^{24}$. Las literas recuerdan a los campos de concentración. Barchiesi explica la situación de los trabajadores negros en Sudáfrica durante el Apartheid:

Black workers could not experience waged employment as part of a decent human life. The conjunction of capitalist domination and racial oppression separated black and white workers and, by admitting only the latter to the full rights of South African citizenship disavowed the idea that work could be a foundation of equality 25 (2011, p.2).

Otros interiores se muestran como lugar de reflexión: la habitación de hotel de Felix in Exile, el hospital de Weighing and Wanting, el interior del coche en el que circula Soho visitando el pasado en History of the Main Complaint, la fábrica desde la que parecen conectarse todos los espacios en Stereoscope o las casetas de playa contrapuestas al hotel en Tide Table. Es en Other Faces en donde la importancia de la urbe es más evidente. Allí se produce el choque entre los dos grupos de población representados en el accidente de coche entre Soho y un hombre negro. En la ciudad aparece varias veces el exterior de la tienda "Horn of Africa" 26 , el espacio donde se fotografía 27 a los ciudadanos, y el espacio de la venta de armas con el letrero "Addis Ababa wholesale" 28 . Muestran una ciudad en la que se han producido cambios, pero

24 En los primeros años del gobierno del Partido Nacional se creó una legislación con acuerdo a la separación de razas. En la Population Registration Act de 1959, los residentes del país se clasificaron como blancos, de color o nativos (Bantu). En los años 30, el barrio de Soweto se creó para alejar a la población negra de las zonas residenciales de población blanca. (Clark \& Worger, 2013).

${ }_{25}$ "Los trabajadores negros no podían disfrutar de un empleo remunerado como parte de una vida decente. La conjunción de dominación capitalista y opresión racial separó a los trabajadores blancos de los negros y, concediendo solo a estos últimos los derechos de ciudadanía sudafricana, rechazó la idea de que el trabajo sirviera como fundamento de la igualdad”. Traducción propia.

26 "Cuerno de África". Traducción propia

27 Las fotografías en la película aluden a la concesión de pases para que parte de la población que tenía su vivienda en las zonas que fueron ocupadas paulatinamente por la población blanca, pudieran quedarse en sus hogares. (Clark \& Worger, 2013).

28 "Addis Abbaba mayorista". Traducción propia 
no necesariamente positivos, porque el discurso de Kentridge es afín a las afirmaciones de Barchiesi respecto al auténtico proceso de sanación y cambio: "Many scholars debating South Africa's post-1994 challenges have linked nation building to political inclusion and racial reconciliation as ways to overcome past injustices and antagonism”29 (Barchiesi, 2011, p. 6).

\subsection{El agua}

Aunque el agua en ocasiones forma parte del paisaje, merece consideración aparte porque es el elemento de representación positiva dentro del texto. El agua, azul, es una de las pocas notas de color que Kentridge incorpora a la serie. Aparece por primera vez en Johannesburg, 2nd Greatest City after Paris en la bañera de Felix, donde produce objetos y dibujos que ilustran su relación sexual con la Sra. Eckstein. El agua es considerada dentro del texto como la esperanza, el proceso de sanación, equiparable a los esfuerzos de la Comisión para la Verdad y la Reconciliación. En alusión al final de History of the Main Complaint, Manchester señala: "Kentridge has left this deliberately open-ended through the bowl of the blue water (symbolizing emotional connection and healing in his films) in Soho's hospital room, which remains untouched through the film"30 (2000, p. 1). Ese recipiente aparece también en Weighing and Wanting, formando parte del peso de los acontecimientos de la balanza y también al final del episodio, cuando la habitación de Soho se inunda (F4) como espejo de lo ocurrido en la habitación del hotel en Felix in Exile. El agua contribuye a borrar la diferencia entre los dos personajes. De hecho, Felix desaparece de la historia en el momento en que empieza a aparecer cierta esperanza.

En Tide Table el agua toma la forma de la orilla del mar. El azul ha desaparecido. En el agua se producen juegos, bautismos, pero también se revela el esqueleto de los muertos por el SIDA. Soho tira al agua piedras que resultarán ser cadáveres. La orilla del mar aparece vacía en el último plano

\footnotetext{
29 "Muchos académicos que han debatido sobre la Sudáfrica posterior a 1994 han vinculado el concepto de construcción de la nación con la inclusión política y la reconciliación racial como forma de superar las injusticias y el antagonismo del pasado". Traducción propia.

30 "Kentridge lo deja abierto deliberadamente a través del recipiente del agua azul (que simboliza la conexión emocional y la sanación en sus películas) situado en la habitación de hospital de Soho, dejándolo intacto durante toda la película". Traducción propia
} 
del episodio. Esta idea de cómo se barren los recuerdos se recoge también en Other Faces, en donde aparecen reiteradamente las palabras: "Shore account" 31 , haciendo del paisaje un testigo de los acontecimientos.

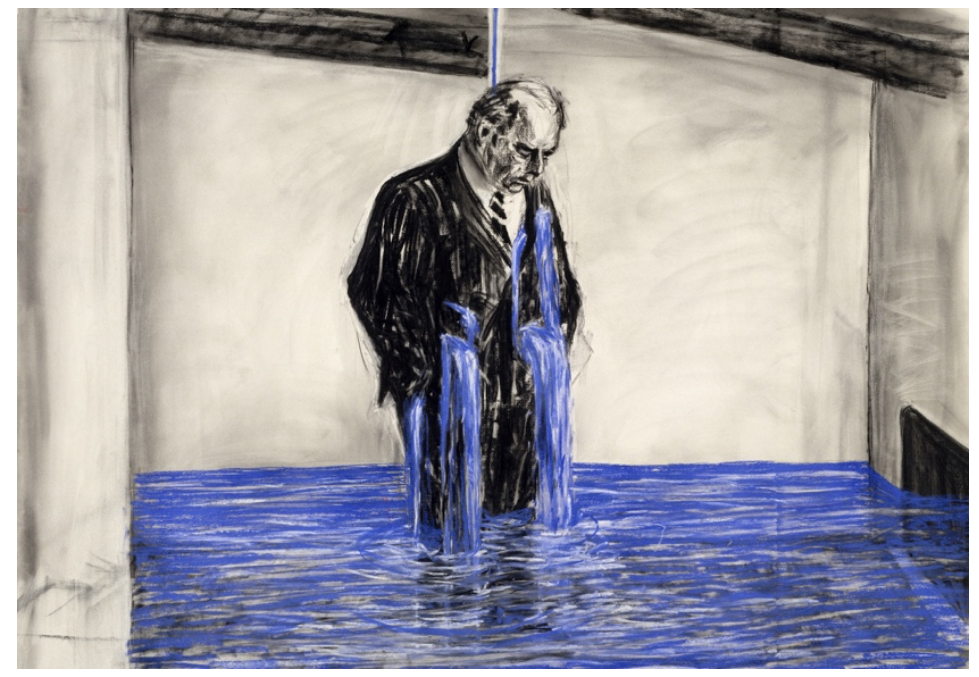

F 4. Weighing and Wanting (1997), William Kentridge. Fotograma de la película.

\section{5•3. Los objetos y su transformación}

La continua transformación a la que Kentridge somete a los objetos que aparecen en la serie indica que todos los acontecimientos se encadenan con una relación causal. La máquina de cálculo de la mesa de Soho produce un recibo, lo que es una relación natural de uso, pero también un recordatorio de que la económica es la única actividad del personaje. En Johannesburg, 2nd greatest City after Paris, esa máquina produce también la hoz y el martillo. Soho rompe la máquina, rebelándose contra las reivindicaciones obreras. Desde una perspectiva opuesta, varios objetos a lo largo de la serie apoyan la idea de observación y valoración, como el espejo, el teodolito (para fijar posiciones), el estereoscopio o el sextante (para mapear el terreno).

En Monument, los micrófonos que se acercan y se retiran de Soho (F5), dirigen sus lenguas lascivamente hacia el rostro del personaje, indicando la connivencia entre los medios de comunicación y la clase dominante. Los papeles que Soho descarta se convierten en megáfonos, contribuyendo a la construcción de la memoria colectiva.

31 "El recuento de las orillas". Traducción propia. 


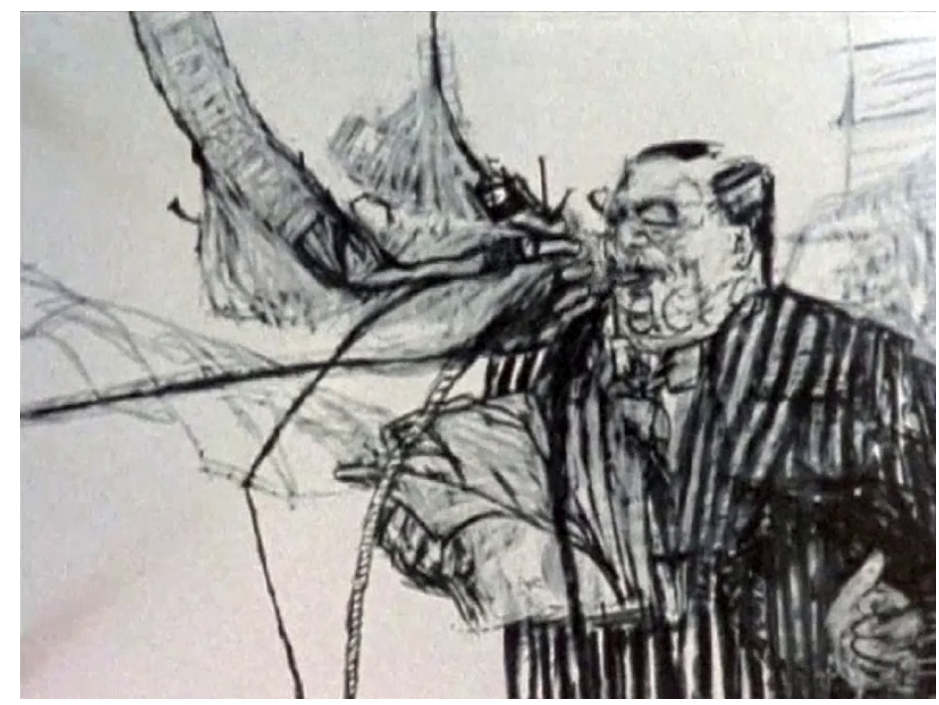

F5. Monument (1990), William Kentridge. Fotograma de la película.

La transformación continua de las noticias del periódico hace alusión a un mundo en ebullición en Tide Table. En Felix in Exile, los papeles cubren los cadáveres, ocultando también la verdad de los sucesos. A partir de Mine, la metamorfosis de los objetos se multiplica. El humo del puro de Soho produce distintas formas. Una de ellas, la campanilla, es la señal de salida para que la maquinaria de la explotación se ponga en marcha. Cuando un grupo de esos trabajadores sale de la mina, las figuras se agolpan para formar la cabeza gigante de un obrero. Esa síntesis alude también a la escultura viviente de Monument. En ocasiones los objetos metamorfosean a otros del mismo campo semántico: en Tide Table, sillas, carretillas, camas, están relacionadas por el dibujo transformador, hablando de la enfermedad y economizando la narración.

Los objetos con una función mecánica, como la máquina registradora, el teodolito, el estereoscopio, la perforadora o los aparatos médicos, despliegan una actividad constante, pero no dan idea de modernidad. Han quedado suspendidos en el tiempo como la centralita en Stereoscope, que conecta toda la actividad en el episodio, hasta quedar agotada. La mecánica de los objetos es la mecánica del pasado. 


\subsection{Personajes y multitudes}

Entre los personajes que complementan a los dos principales encontramos la multitud en procesión ${ }^{32}$, que aparece ya en Johannesburg, 2nd Greatest City after Paris. Los rostros entresacados de la procesión y el individuo que va con muletas recuerdan que la historia se construye a base de casos individuales. Este fue también el recordatorio de la Comisión para la Verdad y la Reconciliación33. Maltz-Leca (2014) señala la multitud como un símbolo del cambio, del proceso. Si en este episodio la multitud es reivindicativa, en Monument funciona como una audiencia de apoyo ante las acciones de la élite. El esclavo que representa la estatua de Monument es parte obvia de la procesión anterior y no de la multitud que aplaude las palabras de Soho. La relación entre la multitud y el individuo representado en el monumento ilustra un pasado esclavista y una celebración cínica del pasado. Así la estatua de Monument se convierte en lo que Karam (2016) denomina el contramonumento, entendiendo por tal un homenaje provocativo, subversivo, que funciona unido a una estética negativa, porque el recuerdo de lo que representa es también negativo. Esa conmemoración del pasado tendrá su continuidad discursiva en los represaliados y los cadáveres aparecen representados en episodios como Felix in Exile o History of the Main Complaint. Los cadáveres que tapan los periódicos en Felix in Exile serán convertidos en piedras y parte del paisaje en Tide Table. Las piedras forman parte también de la alusión histórica personal: en Weighing and Wanting, una roca gigante encierra el pasado de Soho y todos sus anhelos.

En medio de un tratamiento casi colectivo de la población hay sin embargo un personaje autónomo de gran importancia que es Nandi, la cartógrafa, quien dibuja la historia y tiene una conexión especial con Felix. Nandi es la mirada de Felix en el exterior cuando está recluido en su habitación de hotel

\footnotetext{
32 Esa procesión forma parte de otras obras de Kentridge, como el cortometraje. Shadow Procession (1999), que muestra simbólicamente el devenir de las personas que tienen que vivir en una situación de violencia prolongada.

33 La Comisión se creó con la voluntad de que sus audiencias fuesen un acto público para escuchar tanto las opiniones de los sudafricanos como de la comunidad internacional. La población civil, la comunidad religiosa y las víctimas formaron una coalición de más de 50 organizaciones que participaron en este diálogo. Su objetivo era investigar los abusos cometidos sobre los derechos humanos entre 1960 y 1994. (Clark \& Worger, 2013).
} 
(F6). Al ir recuperando datos, se presenta también como la encarnación de la memoria histórica, justificando las palabras de Nora: "we speak so much of memory because there is so little of it left" 34 (1989, p.7). Es precisamente tarea de Nandi evitar que queden pocos recuerdos del pasado. África entonces se transforma en una mujer que cartografía el terreno, que ha ido absorbiendo las atrocidades ocurridas durante años, hasta que pasa de ser observadora a ser víctima. El mensaje que introduce este personaje parece obvio: nadie gana en el proceso. Ese mensaje de pérdida para todos, se refuerza en Stereoscope, cuando se ve por primera vez, el cuerpo de un hombre blanco en el suelo, que parece Soho sin el traje, y comienza a cubrirse de cifras.

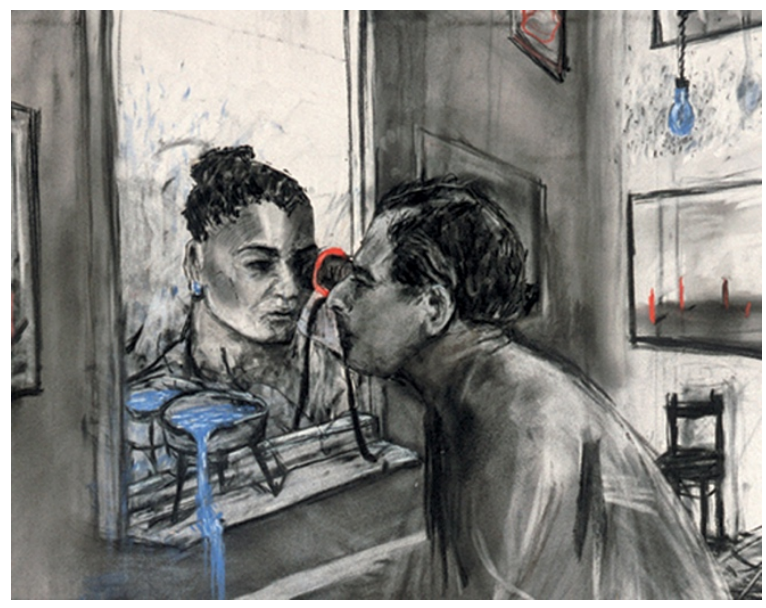

F6. Felix in Exile (1994), William Kentridge. Fotograma de la película.

Kentridge recupera los rostros individuales en Other Faces, un título que funciona en dos direcciones, y que hace hincapié en la separación entre los ciudadanos blancos y negros aún después del final del Apartheid. La población negra se fotografía ante una tela de forma sistemática, como haciendo recuento o registro. La élite blanca aparece en imágenes que imitan películas caseras, con su ocio y sus criados, imágenes reales frente a las imágenes simbólicas que reflejan la irrealidad de la población oprimida.

\subsection{Animales tótem}

Los animales significativos en la serie de Kentridge son: el pájaro, el gato, el pez, el rinoceronte y el buey. Al igual que los objetos, estos animales 
participan del concepto de metamorfosis, funcionan como nexo conductor y representan ideas de modo alegórico. El pájaro puede ser calificado en la serie como el deseo de Felix. No solamente el deseo sexual sino también un deseo de cambio (con respecto a los acontecimientos). Felix desaparece de la serie a partir del quinto título, pero el pájaro permanece y le representa en algunos títulos posteriores. En el primer episodio aparece también un pez que surge de la boca de Felix y se deposita en la mano de la Sra. Eckstein. Ese pez, que pertenece al agua esperanzadora, también está asociado al personaje de Felix. En Sobriety, Obesity and Growing Old estas apariciones animales se afianzan. El gato representa a Soho y también a su matrimonio con la Sra. Eckstein. Los animales totémicos de Felix: el pez y el pájaro, son objetivos naturales del gato (que intentará cazar al pez que salta dentro de la fotografía enmarcada de la Sra. Eckstein). El gato es la tierra (que Soho posee y explota); el pájaro y el pez, aire y agua respectivamente, son medios fundamentales para la transmisión de los mensajes y los discursos, ligándose a la comunicación mediada.

Hay un deseo de libertad en los animales que representan a Felix, pero también lo hay en el de Soho. En Stereoscope, cuando Soho parece más enfrascado en sus negocios, el gato se marcha. La Sudáfrica encarnada en Soho tiene una pequeña esperanza. A través del gato, Soho anhela a su mujer, anhela la libertad y tiempos mejores. Su anhelo no culmina del todo, pero Kentridge lo deposita en el texto como parte de sus deseos para Sudáfrica. El pájaro tendrá una presencia especial en Other Faces, revoloteando en un dibujo casi abstracto. Su posición desde el aire le permite observar todo, acudir a cualquier escenario. Es la función de observador con la que Kentridge se ha quedado al final. El pájaro aparecerá por última vez volando en la pantalla de la valla publicitaria, el lugar para el mensaje.

El rinoceronte, que aparece en Mine también está presente en la versión de La flauta mágica (2011) de Mozart a la que Kentridge aportó sus dibujos. Al igual que en la ópera el sonido de la flauta y la voz del Príncipe Tamino doman al rinoceronte (Kinsman, 2016), Soho lo hace en Mine, como indicativo de que controla hasta los aspectos más salvajes de África. El 
animal aparece en la mesa de Soho, como fruto de las actividades económicas. Es una figura pequeña, que al salir por la puerta de la máquina contabilizadora de Soho, llama la atención del magnate. Soho barre todo lo que hay en la mesa, dejando espacio al pequeño animal, que corre por su mesa y se queda dormido.

Tide Table muestra a los bueyes como representantes de los enfermos de SIDA, uno de los grandes retos para el gobierno posterior a 1994, junto a la corrupción y la falta de financiación (Davenport \& Saunders, 2000). Los bueyes en la playa aparecen, desaparecen, se consumen y sus huesos pasan a ser parte del paisaje. El buey sacrificado, el buey parado, a merced de las mareas, el buey que puebla las noticias del periódico, se relaciona con cifras que vienen y van, como la marea, sujeto a una estructura cíclica. Al final los bueyes se convertirán en las estacas que pueblan el paisaje de la serie, como recordatorio de todo lo perdido.

\section{Conclusión}

A pesar de la cercanía que existe entre las primeras piezas de la serie Drawings for Projection y los acontecimientos históricos referidos, William Kentridge trabaja en la misma dirección que señala Judt (2008), quien avisa de los peligros de sustituir la historia por la memoria, considerando esta última como una recolección parcial de los acontecimientos que en ningún caso puede ocupar el lugar de la historia. Para evitar esa sustitución, Kentridge no trata con el acontecimiento, sino con la reflexión sobre las consecuencias, llevando al espectador a decodificar un mensaje cargado de significado tanto explícito como simbólico.

La utilización del medio artístico y del lenguaje cinematográfico garantiza la monumentalidad a la que hace alusión Capelato (2011). Kentridge recoge esa monumentalidad no como homenaje, sino como exposición de la maquinaria política y económica que ha condicionado la evolución de su país.

El discurso de Kentridge rebate la historia como algo sobre lo que ya no se puede intervenir, optando por un análisis paralelo al que estaba definiendo la 
propia Comisión para la Verdad y la Reconciliación. Mientras la Comisión elaboraba una parte de la memoria oficial de su historia reciente, Kentridge elabora lo que González Calleja (2013) denomina memoria pública, que está a cargo de la voluntad personal o de un grupo social. El autor propone con la metáfora del borrado imperfecto y la fragmentación narrativa un ejercicio de hermenéutica para el espectador de cualquier época y al mismo tiempo obliga a meditar sobre el acontecimiento. En uno de sus ensayos, Kentridge habla del proceso actual de reflexión sobre obras alejadas en el tiempo: "Algunas de las obras que exhibiré tratan de hace una década y algunas de las ideas en torno a ellas de hace seis meses" (2018, p.21). Estas palabras tienen relación con la importancia del contexto transcurrido entre un acontecimiento y su representación o entre una representación y su valoración, lo que justificaría la existencia del décimo título que clausura la serie y que le permite a Kentridge hacer su propia reflexión desde la distancia. En este desarrollo la memoria histórica se manifiesta como una construcción continua desde una única perspectiva, lo que corregiría esa liminalidad de la que habla Westerveld (2010).

Frente a la diferenciación de periodos en su obra que señala Van Caelenberge (2008), y que en este caso partiría la serie en dos intenciones diferenciadas, podemos concluir que esa división no es aplicable a esta serie, cuya coherencia discursiva señala que el concepto de memoria histórica para Kentridge comienza a construirse desde una posición muy cercana a los acontecimientos y sin poder desligarse de su influencia, continúa en construcción hasta el último título.

Kentridge (2018) alude al mito de la caverna de Platón en una de sus conferencias: "el hombre que ha visto la luz y comprendido el conocimiento que de ella se deriva tiene el deber de regresar a la caverna para desencadenar a quienes se encuentran en la oscuridad y elevarlos desde la caverna hacia la luz. De ser necesario, debería hacerse a la fuerza”. (Kentridge, 2018, p.28). En Drawings for Projection Kentridge trata la memoria histórica como una relación indisoluble entre el hecho histórico y 
su responsabilidad como parte integrante de ese hecho histórico, siendo esta última para él, además, una cuestión estética.

\section{Referencias bibliográficas}

Barchiesi, F (2011). Precarious Liberation: Workers, the State and the Contested Social Citizen in Post Apartheid South Africa. Albany: State University of New York Press.

Cabezas, L. (1999). El andamiaje de la representación. En J.J. Molina (Ed), Las lecciones del dibujo (p. 217-336). Madrid: Cátedra.

Cameron, D., Christov-Bakargiev, C. \& Coetzee, J.M. (2003). William Kentridge. London, New York: Phaidon.

Caparrós Leira, J.M. (2007). Enseñar la historia contemporánea a través del cine de ficción. Quaderns de Cine, 1, 25-35. Disponible: http://dx.doi.org/10.14198/QdCINE.2007.1.04

Capelato, M.H., Morettin, E., Napolitano, M. \& Saliba, E.T. (2011). História e Cinema. Dimensoes Historicas do Audiovisual. Sao Paulo: Alameda.

Clark, N.L. \& Worger, W.H. (2013). South Africa. The Rise and Fall of Apartheid. London: Routledge. Disponible: https://doi.org/10.4324/9781315833361

Cubitt, G. (2008). History and Memory. Manchester: Manchester University Press. Disponible: https://doi.org/10.1177/02673231080230040607

Christov-Bakargiev, C. (2017). Carolyn Christov-Bakargiev in Conversation with William Kentridge. En Kraus. R (ed.). William Kentridge (p. 124). Massachusetts: MIT Press.

Dancer, A. (2016). Stereoscope. Critical Commons. Disponible: http://www.criticalcommons.org/Members/andydancer/clips/stereos cope/view

Davenport, T. \& Saunders, C. (2000). South Africa: A Modern History. UK: Palmgrave Macmillan. DOI: 10.1057/9780230287549.

Dubow, J. \& Rosengarten, R. (2004). History as the Main Complaint: William Kentridge and the Making of Post-Apartheid South Africa. Art History 27 (4), 671-690. Disponible: https://doi.org/10.1111/j.01416790.2004.00443.x

Gobby, M. (2018). William Kentridge: The Barbarity of the Great War told through an African Lens. The Conversation. Disponible: http://theconversation.com/william-kentridge-the-barbarity-of-thegreat-war-told-through-an-african-lens-106370)

Godfrey, F. (2014). A Universal Archive. William Kentridge as Printmaker. Research Pack. Hayward Touring. London: Southbank Center. Disponible: 
https://www.aberystwythartscentre.co.uk/sites/aberarts/files/downlo ads/Kentridge\%2520Education\%2520Pack\%2520FINAL.pdf

Gombrich, E.H. (2014). La máscara y la cara: la percepción del parecido fisonómico en la vida y en el arte. En M. Mandelbaum (Comp.), Arte, percepción y realidad. Barcelona: Paidós Estética.

Gomes, Noemia Herdade (2012) Draw - Interactions and extensions in the process, project and artistic work. Case study of William Kentridge. En Barbosa, H. \& Quental, J. (Eds). (2015). Proceedings of the 2nd International Conference of Art, Illustration and Visual Culture in Infant and Primary Education (p. 256-260). São Paulo: Blucher. DOI 10.5151/edupro-aivcipe-49

González Calleja, E. (2013). Memoria e Historia. Vademécum y conceptos y debates fundamentales. Madrid: Los libros de la catarata.

Goyeneche-Gómez, E. (2012). Las relaciones entre cine, cultura e historia: una perspectiva de investigación audiovisual. Palabra Clave 15 (3), 387-414.

https://www.redalyc.org/pdf/649/64924872003.pdf

Disponible:

Halbwachs, M. (2002). Fragmentos de la memoria colectiva. Athenea digital: revista de pensamiento e investigación social, 2, 102-113. Disponible: https://atheneadigital.net/article/view/n2-halbwachs/52pdf-es DOI: $10.5565 / \mathrm{rev} /$ athenead/v1n2.52

Head, T. (21 de agosto de 2019). It's now illegal to display Apartheid Flag in Africa. The South African. Disponible: https://www.thesouthafrican.com/news/why-apartheid-flag-bannedsouth-africa-hate-speech/

Hecker, J.B. \& Kentridge, W. (2010). William Kentridge: Trace: Prints from the Museum of Modern Art. New York: The Museum of Modern Art.

Hirsch, M. (2012). The Generation of Postmemory. New York: Columbia University Press.

Hochberg, J. (2014). La representación de objetos y personas. En M. Mandelbaum (Comp.), Arte, percepción y realidad. Barcelona: Paidós Estética.

Judt, T. (2008). Reappraisals: Reflections on the Forgotten Twentieth Century. New York: Penguin Press.

Karam, B. (2016). William Kentridge's Monument (1996) as Countermonument and the Embodiment of Negative Aesthetics. Image and Text: A Journal of Design, 27 (1), 75-101. Disponible: https://journals.co.za/content/imtext/27/1/EJC193390

Karam, B. (2017). William Kentridge's Animated Drawings for Projection as a Postmemorial Aesthetic. De Arte, 49 (90), 4-23. Disponible: https://doi.org/10.1080/00043389.2014.11877205

Kentridge, M. (2015). The Soho Chronicles: Ten Films by William Kentridge. London: Seagull Books. 
Kentridge, W. (2016). Hope as a Political Category. Arts and Humanities in Higher Education, 15 (1), 11-14. Disponible:

https://doi.org/10.1177/1474022215613601

Kentridge, W. (2018). Seis lecciones de dibujo. Buenos Aires: El Hilo de Ariadna. Colección Ensayos.

Kinsman, J. (2016). William Kentridge: Drawn from Africa. Canberra: National Gallery of Australia. Disponible: https://nga.gov.au/kentridge/magicflute.cfm

Labuscagne, C. (2007). Representing the South African Landscape: Coetzee, Kentridge, and the Ecocritical Enterprise. Journal of Literary Studies, 23 (4), 432-443. Disponible: https://doi.org/10.1080/02564710701786475

Maltz-Leca, L. (2014). Process/Procession: William Kentridge and the Process of Change. The Art Bulletin 95 (1), pp. 139-165. Disponible: https://doi.org/10.1080/00043079.2013.10786110

Manchester, E. (2000). History of the Main Complaint. London: Tate. Disponible: https://www.tate.org.uk/art/artworks/kentridge-historyof-the-main-complaint-to7480

Molina, A. (6 de mayo de 2017). El artista sudafricano William Kentridge, premio Princesa de Asturias de las Artes. El País. Disponible: https://elpais.com/cultura/2017/05/04/actualidad/1493892039 254 175.html.

Montero, J. \& Paz, M.A. (2012). Historia Audiovisual para una sociedad audiovisual. Historia Crítica 49, 159-183. Disponible: http://www.scielo.org.co/pdf/rhc/n49/n49ao8.pdf

Nora, P. (1989). Between Memory and History: Les Lieux de Mémoire. Representations 26, p.7-24. University of California Press. Disponible: https://rep.ucpress.edu/content/26/7 DOI: 10.2307/2928520.

Olick, J.K. (2013). The Politics of Regret. On Collective memory and historical responsibility. New York: Routledge. Disponible: https://doi.org/10.4324/9780203941478

Oppermann, J. (2012). Drawing and mark making in Johannesburg, 2nd Greatest City after Paris. South African Journal of Art History 27 (3), 201-211. Disponible: https://repository.up.ac.za/handle/2263/21521

Rieff, D. (2016). In Praise of Forgetting. Historical Memory and its Ironies. New Haven/London: Yale University Press.

Rosenthal, M. (ed.) (2010). William Kentridge: A Portrait of the Artist. In Five Themes. New Haven/ London: Yale University Press.

Ruiz Vargas, J.M. (2008). ¿De qué hablamos cuando hablamos de memoria histórica? Reflexiones desde la Psicología cognitiva. Entelequia, revista interdisciplinar $7, \quad 53-76 . \quad$ Disponible: https://ideas.repec.org/a/erv/ancoec/y2008i7p53-76.html

Selby, A. (2013). La animación. Barcelona: Blume. 
Sittenfeld, M. (2001). William Kentridge. Catalogue. Belgium: SnoeckDucaju \& Zoon.

Stewart, S. (2005). The Open Studio: Essays on Art and Aesthetics. Chicago and London: The University of Chicago Press.

Thomson, V. \& Laubscher, L. (2006). Violence, Re-Membering and Healing. A Textual Reading of Drawings for Projection by William Kentridge. Southafrican Journal of Psychology. Vol. 36 (4), 813-829. Disponible: https://doi.org/10.1177/008124630603600410

Van Caelenberge, E. (2008). Visual Storytelling: a progressive Strategy? The Animated Drawings of William Kentridge. Imagen [\&] Narrative 23. Disponible:

http://www.imageandnarrative.be/timeandphotography/vancaelenbe rghe.htm

Vogler, C. (2007). The Writer's Journey. Mythic Structure for Writers. Studio City, CA: Michael Wieser Productions.

Wells, P. (2007). Fundamentos de la animación. Barcelona: Parramón Ediciones, S.A.

Westerveld, J. (2010). Liminality in Contemporary Art. A reflection on the work of William Kentridge. (Thesis). Disponible: http://www.judithwesterveld.nl/text/FINAL\%20VERSION\%20THES $\underline{\text { IS\%20(compressed).pdf }}$

\section{Filmografía}

Kentridge, W. (1989). Johannesburg, 2nd Greatest City after Paris. Sudáfrica.

https://www.youtube.com/watch?v=sjdnrnkMSBU

Disponible:

Kentridge, W. (1990). Monument. Sudáfrica. Disponible: https://www.youtube.com/watch?v=vGfZvXT99Ak

Kentridge, W. (1991). Mine. Sudáfrica. Disponible: https://www.youtube.com/watch?v=M8TpcdmCTHo

Kentridge, W. (1991). Sobriety, Obesity and Growing Old. Sudáfrica. Disponible: https://www.youtube.com/watch?v=4fSlWYCxIzU

Kentridge, W. (1994). Felix in Exile. Sudáfrica. Disponible: https://www.youtube.com/watch?v=k5w_CkyPapY

Kentridge, W. (1996). History of the Main Complaint. Sudáfrica. Disponible: https://vimeo.com/231860500

Kentridge, W. (1997). Weighing and Wanting. Sudáfrica. Disponible: https://vk.com/video5520641_161006802

Kentridge, W. (1999). Stereoscope. Sudáfrica. Disponible: http://www.criticalcommons.org/Members/andydancer/clips/stereos cope/view 
Kentridge, W. (2003). Tide Table. Sudáfrica. Disponible:

https://www.youtube.com/watch?v=Zxva06ooIfw

Kentridge, W. (2011). Other Faces. Sudáfrica. Disponible: https://vimeo.com/groups/319358/videos/102311616 